\title{
DOS DOCUMENTOS À PRÁTICA DOCENTE: A IDÉIA DE UMA FORMAÇÃO POR COMPETÊNCIAS
}

\author{
Mikael Frank Rezende Junior ${ }^{*}$
}

\begin{abstract}
RESUMO
O presente artigo tem por objetivo relatar e discutir os principais pontos da palestra intitulada "Interdisciplinaridade, Contextualização e Competências: dos Documentos à Prática Docente", proferida durante o Seminário "Educação por Projetos Interdisciplinares", evento realizado nos dias 09, 10 e 11 de abril de 2008 como projeto de extensão do Centro de Ensino e Pesquisa Aplicada à Educação da Universidade Federal de Goiás. A referida palestra centrou-se na análise crítica de termos como competências, interdisciplinaridade e contextualização, presentes nos documentos propostos pelo MEC após a promulgaçáo da LDB/96 e nas dificuldades e até divergências com a escola brasileira na atualidade. Foram incorporadas neste artigo parte das discussóes levantadas pelos presentes no evento, acrescidas de incursóes teóricas, principalmente no que tange a idéia de uma formação por competências.
\end{abstract}

PalaVras-ChaVE: competências, interdisciplinaridade, contextualização, prática docente.

\section{From documents to teaching practice : the idea of a formation by competencies}

\section{Abstract}

This article has the intent to discuss and report the main subjects of the speech entitled Interdisciplinarity, Contextualization and Competencies: from the documents to teachers practices, which was given during the Seminar: "Education by Interdisciplinary Projects" held in Cepae/UFG on April $9^{\text {th }}, 10^{\text {th }}$ and $11^{\text {th }} 2008$. The speech focused on a critical analyses of terms as competencies, interdisciplinarity and contextualization contained in the documents proposed by MEC after the promulgation of LDB/96 and in the difficulty and even divergencies with the current Brazilian School. Part of the discussions carried through by the audience in the event was incorporated and some theoretical incursions were added, mainly with respect to the idea of a formation by competencies.

KEY WORDS: competencies, interdisciplinarity, contextualization, teaching practices.

\section{INTRODUÇÃo}

Na busca por soluçóes, os problemas da escola em muitos países e cenários têm sido amplamente debatidos e pesquisados nas últimas décadas;

Professor do Instituto de Ciências Exatas - Universidade Federal de Itajubá - MG. Email: mikael@unifei.edu.br. 


\section{Revista Solta a Voz, v. 19, n. 2}

problemas que variam quanto à ordem ou estrutura e que dependem de recursos e interesses. Tais constataçóes podem ser observadas na movimentação de várias naçóes para realizarem reformas em seus sistemas de ensino.

No Brasil, nossa última reforma foi desencadeada há mais de uma década pela Lei de Diretrizes e Bases da Educaçáo Nacional (LDB de dezembro de 1996). Tal reforma foi inspirada não só em demandas internas, mas também a partir de expressivas mudanças na sociedade contemporânea, que acabam impondo novas exigências às pessoas. Assim, é compreensível que a reforma legislacional do ensino brasileiro compreenda náo somente pressupostos políticos ideológicos, mas também busque responder a demandas sociais de modernização da escola, de modo que possa atender à comunidade que nela busca formação para enfrentar as dificuldades que lhe são impostas.

Evidentemente que tais reformas podem afetar a prática dos professores em sala de aula, que já estava sendo questionada mesmo antes dos documentos do Ministério da Educação (MEC). Adjetivamente, foram propiciadas ao professor ferramentas para concretizar uma participação ativa neste processo, ou seja, passar de mero executor das medidas impostas por instâncias superiores para protagonista, ainda que possam ser feitas críticas aos documentos do MEC e das Secretarias Regionais de Educação. De qualquer forma, o momento é importante, pois a própria lei permite aos professores, escola e comunidade a participação ativa e coletiva na elaboração dos projetos político-pedagógicos (PPP) das escolas, onde são assegurados nos textos das Diretrizes Curriculares Nacionais para o Ensino Médio (DCNEM) os pressupostos pedagógicos da identidade, da autonomia e da diversidade.

Nesse sentido, fica claro que a dimensão da reforma pretendida é bem ampla, o que se verifica já na $\mathrm{LDB} / 96$, que estabelece que o Ensino Médio (EM) será a etapa final da educação básica (ver Ricardo, 2002; Ricardo e Zylberstajn, 2002), a partir da qual o aluno receberá uma sólida formação garantindo-lhe o exercício da autonomia crítica. Isso implica bem mais que a revisão de conteúdos a ensinar; sugere a revisão das concepçóes de educação e das práticas em sala de aula.

Porém, publicaçóes mostraram que há certa recusa dos professores aos documentos do MEC, aliada a uma incompreensão de conceitos fundamentais no contexto da reforma proposta, tais como: competências, interdisciplinaridade, contextualização, parte diversificada, núcleo comum, entre outros (ver Ricardo (2005) para análise detalhada e reflexos no ensino das Ciências). 
A resistência aos referidos documentos tem múltiplas razões, que vão desde concepçóes ideológicas variadas até a desconfiança do que seja de fato uma proposta preocupada com o ensino. Outra via de resistência tem sido a estrutura atual da escola, ainda hierarquizada verticalmente, que impóe programas a serem cumpridos e onde o professor é visto como um mero executor, sentindo-se cada vez mais impotente a qualquer mudança em seu exercício profissional.

A dimensão da reforma pretendida para o EM é tal que somente o caráter de terminalidade suscitado por lei para esse nível de ensino já seria suficiente para se rever muitas das práticas ainda correntes na escola. Com esse novo enfoque mudam-se os objetivos da educação média, que deverá assegurar uma formação geral que garanta certa autonomia ao aluno para suas escolhas futuras, quer seja prosseguir nos estudos, o que não se resume ao exame vestibular, quer seja entrar no mercado de trabalho. Esta proposição entra em conflito direto com um ensino nos moldes propedêuticos, por exemplo, no qual o objetivo era preparar para o nível de ensino posterior.

Contudo, há ainda limitaçôes de outras naturezas, por exemplo, a limitação do contingente docente, que é um dos grandes desafios a serem enfrentados. Ainda assim, é preciso enfatizar que a falta de professores não atinge somente o Brasil. Segundo a Organização das Naçóes Unidas para a Educação, a Ciência e a Cultura (UNESCO), há 59 milhóes de professores no planeta, 15 milhóes a menos que o mínimo exigido para atingir a meta fixada no Fórum Mundial da Educação de Dacar, em 2000.

Neste cenário atual, onde as dicotomias acentuam-se a cada instante nas mais distintas esferas que compóem a estrutura organizacional da escola brasileira, serão colocadas em debate as concepçóes teóricas de alguns termos centrais no entendimento dos documentos que regem a educação brasileira, onde se focalizará a idéia de competências devido ao direcionamento sugerido pelos participantes do Seminário "Educação por Projetos Interdisciplinares”, evento realizado no mês de abril de 2008 como projeto de extensão do Centro de Ensino e Pesquisa Aplicada à Educação da Universidade Federal de Goiás (Cepae/UFG).

\section{A estrutura dos documentos para o Ensino Médio}

Explorando os incisos legislacionais vigentes na educação brasileira, cabe inicialmente discutirmos alguns dos pressupostos básicos das DCNEM, 


\section{Revista Solta a Voz, v. 19, n. 2}

que pelo fato de traduzirem (de uma linguagem técnica-legislativa para uma linguagem educacional) os princípios da $\mathrm{LDB} / 96$, acabaram por conferir um caráter de obrigatoriedade à mesma. Por esse fato, nas DCNEM aparecem termos como aprender a aprender, contextualização, competências, interdisciplinaridade, dentre outros; termos que propiciam uma variedade de interpretaçóes e que podem, pela sua rasa compreensão, gerar dificulda-

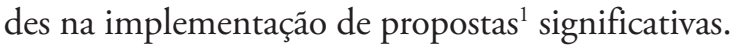

Os termos acima citados têm causado muita discussão pela sua falta de clareza e definição. A noção de competências, particularmente, aparece no Inciso IV, Art. 9 da LDB/96, mas é nas DCNEM que assume a condição de novo perfil para o currículo "apoiado em competências básicas para a inserção de nossos jovens na vida adulta” (Brasil, 1999). Neste caso, a noção de competência está mais ligada a um saber-fazer, ainda que se incluam competências que envolvam a tomada de atitude e a emissão de juízo de valor. Aliás, nas Matrizes Curriculares de Referência do Sistema de Avaliação da Educação Básica (SAEB) há uma definição formal de competências, porém mais ligada ao campo cognitivo.

Deve-se ressaltar que a atual composição de documentos na educação brasileira a partir da promulgação da LDB/96 é rica e diversificada, composição estruturada desde seu caráter de complementaridade até divergências pontuais. Tal ponto é discutido na pesquisa de Ricardo (2005, p. 55), que ao analisar os documentos oficiais e a visão dos seus elaboradores na área de Ciências da Natureza, matemática e suas tecnologias, é enfático ao relatar que "que houve uma influência das DCNEM na elaboração dos PCN, e também o inverso”.

Os PCNs não assumem totalmente os pressupostos e concepçóes das Diretrizes Curriculares. No entanto, pode-se pensar também que os textos das DCNEM são suficientemente amplos em suas abordagens que possibilitam uma grande flexibilidade de interpretaçóes e adequaçóes, já que em sentido amplo, ambos os documentos, Diretrizes e Parâmetros, não se contrapóem. (Ricardo, 2005, p. 56)

Conjuntamente à idéia de competências, outros termos também têm incitado a discussão nos campos teóricos e aplicados, como interdis-

1 Esta posição sugere conflitos entre o contextualizar e a interdisciplinaridade, mas não trataremos aqui de conceitualizar e discutir essas idéias. 
ciplinaridade e contextualização. Sobre a idéia de interdisciplinaridade, as DCNEM apontam que:

Na perspectiva escolar, a interdisciplinaridade não tem a pretensão de criar novas disciplinas ou saberes, mas de utilizar os conhecimentos das várias disciplinas para resolver um problema concreto ou compreender um determinado fenômeno sob diferentes pontos de vista. Em suma, a interdisciplinaridade tem uma função instrumental. Trata-se de recorrer a um saber diretamente útil e utilizável para responder às questôes e aos problemas sociais contemporâneos. (Brasil, 1999, p. 34)

No decorrer das DCNEM, a noção de interdisciplinaridade assume um caráter amplo, abrangendo tanto aspectos pedagógicos como cognitivos, didáticos e relacionais. Já a idéia de contextualização apresenta-se nas DCNEM associada à busca de significado para o conhecimento escolar, pois para este documento há um distanciamento entre os conteúdos disciplinares e a experiência dos alunos, e este precisa ser superado. Há ainda um entendimento por parte das DCNEM relativo à contextualização quanto à possibilidade de ampliar a interação entre as disciplinas (síntese do depoimento de um professor durante a palestra aqui relatada). Em outro momento, contextualizar já significaria admitir uma relação entre sujeito e objeto em todo processo de conhecimento.

Apesar de seminais para um entendimento mais amplo da idéia de competências, ou ainda, de um currículo por competências, não será apresentada aqui uma discussão sobre contextualização e interdisciplinaridade. Contudo, indicamos para um aprofundamento a leitura do capítulo $5 \mathrm{da}$ tese de doutoramento de Ricardo (2005).

Retomando a especificidade e a sua contribuição no arranjo dos documentos que compóem a legislação educacional vigente no Brasil, tanto os Parâmetros Curriculares Nacionais (PCN) como os Parâmetros Curriculares Nacionais: Orientações Educacionais Complementares aos PCN $(\mathrm{PCN}+)$ tiveram como base a LDB/1996 e a DCNEM, e surgiram no intuito de oferecer subsídios para o trabalho a ser realizado nas escolas, mais especificamente nas disciplinas. Os $\mathrm{PCN}$ são compostos pelos próprios Parâmetros Curriculares, da resolução 03/98 do CEB/CNE que estabelece as DCNEM e da LDB/96, assim, muitas críticas feitas aos PCN deveriam ser, na verdade, dirigidas às DCNEM. Da mesma maneira, muitas críti- 
cas feitas às DCNEM, ao serem transpostas aos PCN, deveriam ser feitas de modo judicioso, pois nestes é preciso considerar as especificidades das diversas áreas.

Os PCN, assim como os PCN+, têm como objetivo fornecer subsídios aos professores em suas respectivas áreas, no intuito de reorientar o ensino, que deixaria de ser centrado exclusivamente no conhecimento e almejaria a construção de competências e habilidades. Mas parece haver, entre outros pontos, grandes limitaçôes, pois quase dez anos após a aprovação da LDB/96 pouco se tem constatado em termos de mudanças. Tal observação é destacada por Ricardo e Zylberstajn (2003, p. 2):

No entanto, embora esses documentos ofereçam subsídios aos professores para a distância entre o que está proposto e a prática escolar, cuja superação tem se mostrado difícil. Essas dificuldades vão desde problemas com a formaçáo inicial e continuada à pouca disponibilidade de materiais didático-pedagógicos que estejam em consonância com os fundamentos da proposta de reforma; desde a estrutura verticalizada dos sistemas de ensino, à incompreensão dos pressupostos da lei, das Diretrizes Curriculares e dos Parâmetros.

Conforme ressaltado, primordialmente faltam aos docentes subsídios para uma interpretação crítica das bases legais da educação nacional, o que desencadeia um desencontro no sistema educacional, estigmatizando ainda mais a relação "teoria-prática", que em um sentido "realista" pode ser traduzido como: "o papel aceita tudo [...], mas na sala de aula temos outra realidade [...]” (Brasil, 2006/2007, s/p).

Buscando contornar esses percalços, no final de 2004 o MEC publicou e trouxe para a discussão textos desenvolvidos por professores atuantes na área de formação docente no intuito de subsidiar reformulaçóes/adaptaçóes necessárias, apresentando-os em seminários regionais. Da releitura sobre os documentos (PCN, PCN+, DCNEM, LDB/96) originou-se a versão base das Orientaçóes Curriculares do Ensino Médio (2004). Nessas orientaçôes são sugeridas reflexôes sobre os conteúdos, como também as práticas escolares num sentido mais amplo.

A constituição de um cidadáo contemporâneo, capaz de compreender seu mundo, dificilmente ocorrerá por meio de conteúdos envelhecidos didaticamente, cujo ensino persiste muito mais "consagrado pelo uso" do que 
por sua pertinência na formação geral do aluno. Ou seja, há necessidade de rever os conteúdos a ensinar, mas não só, uma vez que também as práticas escolares teriam que passar por constantes avaliaçôes, reflexôes e que resultassem em novas açôes. (Brasil, 2004, p. 194)

A continuidade do referido trabalho aconteceu durante o ano de 2005 e culminou com a divulgação da versão final das Orientações Curriculares para o Ensino Médio em 2006², que consiste em uma possibilidade de compreensão para os pressupostos fundamentais presentes nas DCNEM, nos PCN e PCN+.

Contudo, documentos podem carregar intençôes, mas se tornarão simplesmente "papéis oficiais" se, conjuntamente, não forem instituídas políticas públicas para dar suporte a tais iniciativas, principalmente no que se refere ao necessário suporte à prática docente, já que os problemas da escola são muitos e atendem por diversos nomes. Até poderíamos categorizá-los, mas isso não vem ao caso. Muitos desses problemas, inclusive, não se limitam à escola, e nada mais são do que reflexos de décadas de descaso geral com a educação básica no Brasil.

\section{A FORMAÇÃO POR COMPETÊNCIAS E A PRÁTICA DOCENTE}

Mesmo após a promulgação da LDB/96, quando o aparecimento da noção de competências começa a ganhar força no cenário nacional alicerçado com o surgimento de vários livros que tratam dessa temática, dentre os quais se destacam as traduçóes para o português dos livros de Phillipe Perrenoud, é notório que a idéia do que venha a ser um ensino por competências está distante da sala de aula e da prática docente de professores da educação básica.

Para este autor (1999, p. 7), uma definição para competências é "a capacidade de agir eficazmente em um determinado tipo de situação, apoiada em conhecimentos, mas sem limitar-se a eles”. Entretanto, Perrenoud ressalta que desenvolver competências nos estudantes não é uma nova moda, mas sim um retorno a uma das funçốes da escola, qual seja dar utilidade aos seus ensinamentos.

2 Um exemplo atual pode ser extraído da leitura de "A influência da mudança da legislação na formação de professores: as 300 horas de estágio supervisionado”, de Carvalho (2001). 
Sobre esse ponto é necessário enfatizar que não cabe à escola ou aos professores ensinar diretamente essa ou aquela competência, mas que está na escola o dever de reestruturar a sua própria concepção, visto que é preciso repensar os objetivos educacionais, já que uma das implicaçóes do que seria um ensino por competências tenciona mudar o ponto de partida, ou seja, não só as práticas docentes como também os conteúdos, onde um dos seus objetivos seria a criação de condiçôes para o desenvolvimento das competências almejadas.

Contudo, ainda que trabalhos tenham relatado a dificuldade acerca da noção de competências, educadores e teóricos da educação entendem que se trata de uma nova forma de olhar os conteúdos escolares e as escolhas das respectivas abordagens, ainda que não exista consenso sobre a sua aceitação como prática pedagógica.

Não é forçoso esclarecer que a utilização do termo aceitação é motivo para qualquer tipo de indagação conflituosa, visto que em qualquer tentativa de dar respostas ao atual fracasso escolar sempre incorrerá em risco de discordâncias e inquietaçóes.

É justamente nesse sentido que estamos afirmando que a mera superposição dos saberes prévios dos alunos pelos saberes escolares não é sinônimo de aprendizagem, visto que este, na maioria das vezes, é substituído assim que o jovem se vê fora dos muros e das regras escolares. Assim, cabe mais uma vez ao professor, em sua prática docente, assumir que a verificação dos processos de aprendizagem, quando restrita às situaçóes escolares, está mais voltada para a revelação de comportamentos do que de operaçóes mentais que integram novos elementos nas estruturas cognitivas já existentes, o que em outras palavras significaria dizer que não explicita necessariamente competências.

E é justamente nesse processo de decisão e escolha que a prática docente se insere na construção de um currículo por competências, que advém justamente da necessidade de refletir sobre o fato de que "as competências não se opóem aos saberes, mas ao acúmulo de informações e de pré-requisitos fragmentados como fim" (Ricardo, 2005, p. 154).

\section{ConsideraÇóES FINAIS}

Tratar a idéia de competências como uma questão atual no cenário educacional brasileiro, seja no âmbito legislacional, de pesquisa ou na 
prática docente, não é uma idéia original; vários autores têm se dedicado a essa tarefa e reforçam um quadro de ampliação da produção de trabalhos acadêmicos (André et al., 1999).

Ademais, é preciso ressaltar que quando se toma como base as principais referências teóricas que chegam a pesquisadores e docentes, não deve ser motivo de indagação as diversas interpretaçóes que emergem dessas leituras, principalmente pelo fato de que tais referenciais utilizam diversos termos da didática, sociologia, pedagogia, filosofia etc., que se constituem como verdadeiros impasses teóricos aos leitores, a citar como exemplo: teoremasem-ação, práticas sociais de referência etc. E nesse caminho ainda longe de qualquer aproximação imediatista encontra-se a idéia de competências ou de composições não menos inquietantes como a formação por competências.

E passos já foram dados. Contudo, é preciso empenho das mais distintas esferas para que os professores e profissionais da área tenham acesso, e principalmente tempo, para se dedicarem aos documentos que legislam na atual educação brasileira, seja na formação inicial ou na formação continuada, para que as sugestóes propostas nestes possam ser implementadas, discutidas, aprimoradas e até mesmo rejeitadas, mas que não se tornem simplesmente documentos históricos, e sim uma proposta efetiva na prática docente.

Momentos de debate como os propiciados com a realização do Seminário "Educação por Projetos Interdisciplinares" em Goiânia-GO são e sempre serão os bastidores de um cenário que necessita de constante dedicação das mais variadas áreas, pois se trata de um cenário amplo, complexo e em constante mudança: a escola básica brasileira.

\section{REFERÊNCIAS}

ANDRÉ, M. et al. Estado da arte da formação de professores no Brasil. Educação \& Sociedade, Campinas, v. 20, n. 68, p. 301-309, dez. 1999.

BRASIL. Lei no 9.394, de 20 de dezembro de 1996. Estabelece as Diretrizes e Bases da Educação Nacional. Diário Oficial [da] República Federativa do Brasil. Poder Executivo, Brasília, DF, v. 134, n. 248, p. 27833-41, 23 de dezembro de 1996. Seção 1, Lei Darcy Ribeiro.

BRASIL, Ministério da Educação, Secretaria da Educação Média e Tecnológica. Parâmetros Curriculares Nacionais: Ensino Médio. Brasília: Ministério da Educação, 1999. 360p. 


\section{Revista Solta a Voz, v. 19, n. 2}

BRASIL, Secretaria de Educação Média e Tecnológica. PCN+ Ensino Médio: orientaçóes educacionais complementares aos Parâmetros Curriculares Nacionais. Ciências da Natureza, Matemática e suas Tecnologias. Brasília: ME; SEMTEC, 2002. 144p.

BRASIL, Ministério da Educação, Secretaria de Educação Básica, Departamento de Políticas de Ensino Médio. Orientaçóes Curriculares do Ensino Médio. Brasília: MEC; SEB, 2004. 400p.

BRASIL, Ministério da Educação, Secretaria de Educação Básica. Politicas de Ensino Médio. Portal MEC / Sitio SEB, 2006/2007. Disponível em: $<$ http://portal.mec.gov.br/seb/index.php?option=content\&task=view\&id $=409 \&$ Itemid $=395>$.

CARVALHO, A. M. P. A influência da mudança da legislação na formação de professores: as 300 horas de estágio supervisionado. Ciência e Educação, Bauru, v. 7, n. 1, p. 113-122, 2001.

PERRENOUD, P. Práticas pedagógicas, profissão docente e formação: perspectivas sociológicas. Lisboa: Publicaçóes Dom Quixote, 1997.

- Construir as competências desde a escola. Trad. de Bruno Charles Magne. Porto Alegre: Artes Médicas Sul, 1999. 90p.

- A prática reflexiva no oficio de professor: profissionalização e razão pedagógica. Porto Alegre: Artmed, 2001. 232 p.

RICARDO, E. C. As Ciências no Ensino Médio e os Parâmetros Curriculares Nacionais: da proposta à prática. Ensaio: Avaliação e Políticas Públicas em Educação, Rio de Janeiro, v. 10, n. 35, p. 141-160, 2002.

A reforma educacional e as Ciências do Ensino Médio: dificuldades de implementação e conceitos fundamentais. In: ENCONTRO NACIONAL DE PESQUISA EM EDUCAÇÃO EM CIÊNCIAS, 4, 2003, Bauru. Atas... Bauru: SBF, 2003.

. Competências, interdisciplinaridade e contextualização: dos Parâmetros Curriculares Nacionais a uma compreensão para o Ensino das Ciências. 2005. 245f. Tese (Doutorado em Educação Científica e Tecnológica) Centro de Ciências Físicas e Matemáticas, Centro de Ciência da Educação, Universidade Federal de Santa Catarina, Florianópolis, 2005. 
- ZYLBERSZTAJN, A. A reforma educacional e as Ciências do Ensino Médio: dificuldades de implementação e conceitos fundamentais. In: IV Encontro Nacional de Pesquisa em Educação em Ciências, 2003, Bauru. IV ENPEC, 2003.

- O ensino das Ciências no nível médio: um estudo de caso sobre as dificuldades na implementação dos Parâmetros Curriculares Nacionais. Caderno Brasileiro de Ensino de Física. Florianópolis, v. 19, n. 3, p. 351-370, dez. 2002.

Recebido em: 10 set. 2008 Aceito em: 20 out. 2008 